\title{
Development of Integrated Horticulture based on Investments (In the Case of Uzbekistan)
}

\author{
Mahmudov Nosir Mahmudovich, Dadaboev Tulkinjon Yusupjonovich
}

\begin{abstract}
Thanks to the introduction of modern management strategies in the world, the scale of the effective integration of industry into innovative development of the industry has been expanding. Therefore, the article outlines the implementation of modern innovative management strategies, improvements in agricultural production, particularly in the production and processing of horticultural products, the supply of raw materials for the industry, their integration, and the impact of factors affecting the production process.

Purpose - Development of suggestions on improving investment in the field of gardening and using them effectively.

Design/methodology/approach - During the research, comparative analysis, abstract thinking, economic calculations, expert assessments, monographic observation and econometric analysis were used.

Originality/value - The relevance and accuracy of the approaches and methods used in the research is determined by the fact that the statistical data is based on the data of the State Statistics Committee of the Republic of Uzbekistan and other officially published data, and the relevant conclusions.
\end{abstract}

Keywords : agriculture, agrarian sectors, horticulture, integration, investment, processing, storage, econometric modeling, prognosis.

\section{INTRODUCTION}

Stabilization of agrarian sector development in the republic and development of horticulture sector in providing population with quality foodstuffs play an important role. Presence of nutrients and, in most cases, irreplaceable natural chemical compounds (sucrose, glucose, fructose, organic acids, vitamins, microelements, etc.) necessary for human health and activity in the field of nutrition enhance their importance as foodstuffs.

The country has a long history of horticulture, with the natural and climatic conditions in the region being one of the most important factors that contribute to the development of horticulture, such as the sunny days of the year, the adequacy of rainfall in the mountain and fishing areas. The rich experience accumulated over many years of the ground has expanded opportunities in this area.

Horticulture in the Republic is well developed in irrigated farming zones, but it can also be engaged in grazing gardening (in the hilly areas at the altitude of 750-1600

Revised Manuscript Received on October 15, 2019.

* Correspondence Author

Mahmudov Nosir Mahmudovich, Professor of Tashkent State Economic University, Uzbekistan.

Dadaboev Tulkinjon Yusupjonovich, Associate Professor of Namangan Engineering Construction Institute, Namangan, Republic of Uzbekistan. meters above sea level). In mountainous areas, at an altitude of 2500-2800 meters above sea level, the availability of favorable climatic conditions for habitats creates more convenience than horticulture. Although they are relatively less fertile than these, they have the potential to make efficient use of land resources by building frogs, walnuts, cherries and almonds.

However, it should be noted that the implementation of sector-based reforms in the Republic of Uzbekistan contributes to the development of horticulture and the availability of a number of tasks and problems that should be implemented in the sector, although it is likely to lead to scientific research and research in the industry.

Particular attention should be paid to the development of the sector in promoting the integration of horticultural production, procurement, processing, storage and sales. Because of the fact that any production is based on the market demand, businesses in the closest segments of the consumer should have a link to the farmer "what to order" the quantity, size, quality and appearance of the products in the market (Figure 1).

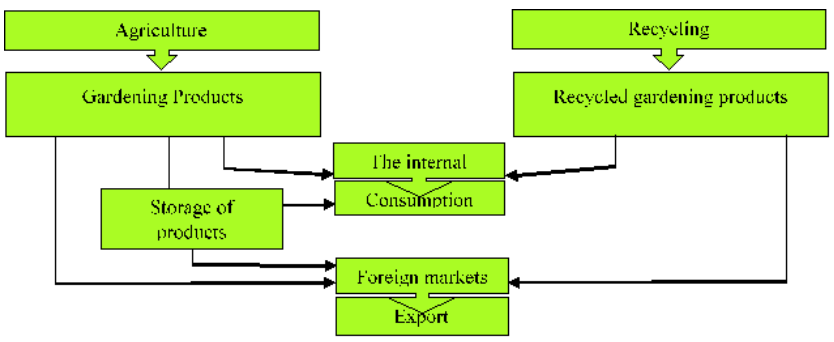

Figure 1. The structure of the production, processing and consumption of horticultural products

Analyzes indicate that while most of the country's horticultural crops die without going into the market, large-scale farmers are selling apples, pears, fruits and grapes imported from outside the country. Despite the fact that the imported fruits in our country are not able to compete with the fruits of the taste levels and the level of their usefulness for the human body, it is distinguished by the appearance, the way of packaging, and the buyer's attractiveness. Therefore, it is necessary to develop recommendations on the development of mechanisms for increasing the competitiveness and competitiveness of the future gardener products. 
It should be noted that deepening the specialization of farming in the field of gardening will make it possible to wider use of natural and climatic conditions of the regions. Developing proposals and recommendations on the mechanisms of economic, financial support for the development of horticulture and the development of integrated horticulture on the basis of investment, the development of a new sales, storage, transportation system, as a matter of fact.

\section{LITERATURE REVIEW}

Nowadays, the issues of addressing the need for food for the population of the world are being studied extensively. In particular, the theoretical foundations of innovation in agriculture, its organizational and economic nature, the necessary conditions for development and its impact on the effectiveness and sustainable development of industrialized countries on the example of I.G. Ushacheva, E.S. Ogloblina, I.S. Sandu, AI Trubilina (2006) pointed out that the development of agriculture mainly depends on regional factors, such as the availability of natural resources, some climatic, socio-economic, investment and innovative conditions, as EM Chemeris (2014), a nature that protects natural systems in the developing world and covers the public preserving the balance of positive developments for the development of the environment and the food security and the diverse diversity of workers planned for protection A.D. Basiago (1999) done.

James McEldowney (2017) also points out the disparities in the future with increased concerns about climate change, including urban populations over urban populations, interest in agriculture and food security, and eliminating these problems Finding new consumer goods in their production, their localization A.Asfaw (2008), the advantages of using the home garden and the cost-effectiveness of home gardening UN Kumar and PK R. Nair (2004), from the city's food-gardening to urban farming, S. Rojo et al. (2015) Development of Urban Agriculture Design Strategy by G. Kouffe (2016), Urban Food Urban Planning in Today Towns A. Jenkins (2015), Assistance to Food Safety in Urban Areas I. Opitz (2016), Investment Efficient Use and direct interdisciplinary distribution Sina JK (2017) and Bahodirzhan B (2017).

Despite the substantial contribution of these learned foreign researchers to economics, the development, specificity, climate, and population of the country's economy are not considered. This, in turn, serves as an important factor in defining and predicting future food security and food security. In this sense, it implies more broader and deeper scientific research within the chosen subject.

\section{HYPOTHESES}

The development of the horticultural sector requires the full and effective use of the industry, regardless of what is being done through the manufacturing sector or through the agro-industrial companies. The peculiarities that should be taken into account in the development of livestock farming businesses should, in our opinion, be two groups

H1. Specific features related to production activities in the field of indirect gardening.
According to the first hypothesis, it is necessary to take into account the diversity of the composition of the gardening products and the issue of the production of products of different appearance, character and composition. In gardening, along with the production of many types of products, the characteristics of the product are exceptionally distinct from the appearance, the characteristics of the goods, and the differences in consumer purchasing goals (consumption).

Also, gardens can not be changed quickly (not economically self-justified) because of the process of gardening in farming enterprises and the production of the garden in question. The excessive wealth and labor of the owner of the garden lead to inefficient expenditure. For example, in the plum garden, which has been created without taking into account regional markets or sales opportunities, 4-5 years after the tree's harvest, it becomes more difficult to sell cereal in local markets, well-selling peaches and high yields. However, plots of plenty of plenty of money associated with the creation of the old garden, without distorting the plum tree and sowing peaches, are spent unspeakably, and, secondly, a certain period of time before the new gardens begin to yield. Therefore, farmers need to thoroughly study the markets of fresh fruits grown in the creation of new gardens or restoration of old gardens.

$\mathrm{H} 2$. Specific features related to the activity of indigenous farms.

According to the second hypothesis, the number of horticultural products grown on these farms is small, with the fact that the farming enterprises established in the field of horticulture constitute an average of 2.0-2.5 hectares. This, in turn, leads to impediments to the development of production;

- Sufficient knowledge, skills and expertise are required from heads of farming enterprises producing horticultural products;

- farming in the field of gardens is often away from the cultivated farming areas in mountainous and foothill areas of the country. Hence, because of the fact that they are far away from major and large markets, there is a traffic issue associated with the marketing of goods during the ripening period and the acquisition of material and technical resources;

- The possibility to organize production on an intensive basis is great opportunities not only for irrigated farming, but also for the development of horticulture in tropical and mountainous and foothird areas. Horticulture plays an important role in the effective use of rocky soils in the mountains in winter and spring, where moisture and precipitation,

- As noted above, the production of gardening products requires the managers of farms to produce different types of fruits and vegetables, and to adopt methods and rules for the care of trees. It is noteworthy that one of the important features of the development of farms is that not only each fruit tree species, but also the varieties of trees of one species, - As the field of horticulture is largely a branch of handicraft, it is more difficult to build gardens in the mountainous areas, to process it and to use mechanization. It is also necessary to take into account

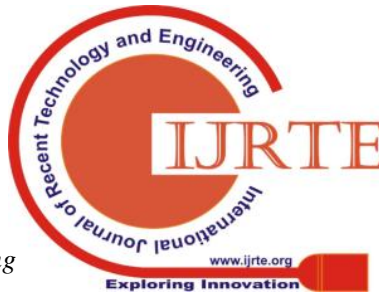


the fact that the financial condition of the horticultural farms is not satisfactory, and that the current level of mechanization of the production process should be further reduced and the manual processing of basic processes should be taken into account in the development of farms in the regions of the country;

- It is well known that experience in the field of gardening, the secrets of crop production in the country, and the transition from generation to generation, mostly in the gardeners, will lead to the establishment of family farming in this area. In horticultural farming, hired workers are mainly involved in land reclamation and harvesting. Therefore, starting a new horticulture business has some difficulties, requiring a farmer to gain experience and knowledge of gardening and gardening.

Therefore, farmers need to have the resources to finance such activities (considering that investment in the establishment of new gardens does not change economically until the gardens enter the crop), they must plan for the availability of material and labor resources.

Measures should be taken to protect the farmers from financial losses in areas where natural and climatic conditions are rapidly changing and that occur frequently in natural disasters such as heavy rainfall and snowfall, early spring unexpected frosts. At the same time, it is expedient to use the insurance tools together with the economic and financial protection measures.

Hence, the development and implementation of measures for the development of farms in the gardening sector is one of the peculiarities of the industry, taking into account the peculiarities of each region and its effective use, the development of integrated horticulture based on investment is the key to the economic stability of such farms.

\section{METHOD}

In the context of the development of market relations, what is the final outcome of integrated horticultural farms on the basis of investment and sales, depends on the extent to which macroeconomic and macroeconomic organizational and economic mechanisms are set.

Using experiences gained in foreign countries in developing horticulture or comparing our abilities with the results achieved in foreign countries plays an important role in determining the future gardens network. In particular, the problem of fruit growing in Russia is interpreted as the direction of the country's food problem. However, according to EastFruit (2018) analysts, imports of about 770,000 tons of apples to Russia in 2018 will increase, up from 60,000 to 70,000 tons last year. Generally, imports of apples to Russia in the 2018/19 season (August-July) can reach 800,000 tons for the first time since 2015. Because low productivity does not allow for a sufficient number of fruits to be produced by the farmers, and, as a result, limits investment opportunities in the industry.

Also, one of the most important events in the field of gardening development in the Russian Federation is one of the most important events for our republic, the specialization of fruit trees in agro-tourism and the creation of integrated horticulture on the basis of investments. An important factor in this is the great attention paid to such factors as average annual sunlight, temperature, moisture regime and soil fertility A.M. Belykh (2006).

The conditions of the Republic are favorable for gardening, and the issue of regional specialization is very important, despite the presence of an unlimited amount of solar energy and heat. Because, it is necessary to take into consideration the other factors. In particular, it is necessary to take into account that tolerance to soil fertility and moisture content or resistance to acute variability of climatic varieties has differently adapted to fruit trees.

Today, scientists are proposing ways to intensify the field of horticulture, to improve the technical equipment, to develop the specialization of production, to develop and maintain the products, to widen the use of cooperative principles in the production of products from the production of the product to the consumer Shalyapina I.P. (2006).

In this regard, the directions for the development of the fruits storage system are quite remarkable for our country. In particular, the use of the gas-fertile storage of fruit-and-vegetable farming has significantly expanded, in which attempts are made not only to improve the storage technologies, but also to adapt to fruits preservation. It should be noted that the following main elements of improvement of the fruits preservation system should be noted: Shalyapina I.P. (2008):

- creation and placement of disease-resistant and conserved varieties;

- Development of optimal rates of agro-technical measures (soil composition, gardening, gardening, pest and disease control);

- Targeted cultivation of fruit by pre-selected parameters (on the basis of market demand, appearance, quality and shape); - It is also important to pay attention to the directions of creation and maintenance of the scheme of sales of the products from the warehouse.

Based on these views, the development of horticulture will enable them to attract investments, effectively utilize them for the development of integrated horticultural investment and to assess their current status, volume of production, storage, delivery losses, it is necessary to carry out economic analysis of yields. It should be noted, however, that the development and future forecasting of econometric models using these factors will also allow for a certain degree of planning and decision-making.

\section{RESULTS}

The development of the horticulture industry should be based on the effective use of agricultural production and regional features. It should be noted that along with the seasoning of the crop, some types of horticultural products should also be taken from early spring to late autumn (eg, early spring, summer and autumn-winter varieties of berries), as well as very good storage of walnuts (almonds, almonds). These features play an important role in organizing the product launch process and integrating specialized networks.

Today, in the Republic of Uzbekistan, instead of liquidated shirkats, private farms have emerged and operate. Most of these $(100 \%)$ are farms producing horticultural, 
vegetable or grain crops. This testifies to the wide range of prospects for the sustainable development of the horticultural network. It can also be tracked by indicators for the development of the horticulture industry. In particular, the area of gardens has increased in the republic, despite the fact that it is very slow. This figure was 139.2 thousand hectares in 2000, reaching 287.1 thousand hectares in 2017, an increase of $153.5 \%$ compared to 2000 (Table 1).

Table 1: Dynamics of changes in gardening indices across the country (thousand ea)

\begin{tabular}{|l|c|c|c|c|c|c|}
\hline Indicators & $\begin{array}{c}2000 \\
\text { year }\end{array}$ & $\begin{array}{c}2005 \\
\text { year }\end{array}$ & $\begin{array}{c}2010 \\
\text { year }\end{array}$ & $\begin{array}{c}2015 \\
\text { year }\end{array}$ & $\begin{array}{c}2017 \\
\text { year }\end{array}$ & $\begin{array}{c}\text { Compared to 2000, the change } \\
(-,+)\end{array}$ \\
\hline Area (thousand le) & 139,2 & 208,2 & 235,3 & 270,3 & 287,1 & 147,9 \\
\hline Productivity (ts / ha) & 56,8 & 62,3 & 72,7 & 101,6 & 107,2 & 50,4 \\
\hline Gross yield (thousand tons) & 790,6 & 949,3 & 1710,3 & 2746,1 & 3076,3 & 2285,7 \\
\hline
\end{tabular}

According to the data of the table, in 2000, 790.6 thousand tons of fruits were grown, and by 2017 it increased by $2,285.7$ thousand tons to 2,076.3 thousand tons. One of the main reasons for this is the increase in the number of shirkats that specialize in horticulture and the strengthening of farming in the country. The main factor influencing the change in the area of crops is the growth of the crop capacity. This is a serious basis for increasing productivity, searching for opportunities for intensive development of the sector, and enhancing the effectiveness of inputs on the basis of integration of enterprises in the industry.

The fertility of gardens leads to the weakening of the financial condition of the horticultural farms, which have a very high potential for lower yields, lower crop yields, higher product cost and lower market prices. This, in turn, contributes to the deterioration of the material and technical base of the horticultural network.

Horticulture is based on the principle of full free market in our country, and the development of the industry is not the methods that are based on the inertia left from the administrative command system, but rather the network service systems, mineral fertilizers, fruit trees and various insecticides, horticultural equipments as well as a single-industry event in a competitive environment for the production of various equipment and sales to farmers the lack of sufficient financial resources for businesses. As a result, the level of profitability of the network with new techniques and technologies, improving the quality of products, and most importantly, fruit production remains lower than expected.

It is desirable to have econometric modeling on the scientific justification and to make analyzes on this basis. Regression calculations and the selection of best, reliable and adequate regression equations in implementing econometric analysis are key factors in the effective economic analysis of market con- ditions. Exact and reliable data and econometric analysis of economic objects determine the accuracy of the results. In this sense, econometric-mathematical models and methods provide the optimal decision in the current situation.

To do so, it is necessary to select reliable and effective factors. As a result, the total output of fruit-and-vegetable crops - Y, the volume of investment in fruit production - X1, the number of bushes in the field - X2, and the allocation area X3 factors. First of all these factors are determined by the correlation coefficient in the EXCEL program (Table 1).

Table 1:Correlation analysis of selected economic indicators of the gardening of the Republic of Uzbekistan

\begin{tabular}{|c|c|c|c|c|}
\hline & $\boldsymbol{Y}$ & $\boldsymbol{X}_{1}$ & $\boldsymbol{X}_{2}$ & $\boldsymbol{X}_{\mathbf{3}}$ \\
\hline $\boldsymbol{Y}$ & 1 & & & \\
\hline $\boldsymbol{X}_{\mathbf{1}}$ & 0,974406 & 1 & 1 & \\
\hline $\boldsymbol{X}_{\mathbf{2}}$ & 0,827133 & 0,731672519 & 0,7542487 & 1 \\
\hline $\boldsymbol{X}_{\mathbf{3}}$ & 0,895649 & 0,688735659 & & \\
\hline
\end{tabular}

Source: author's work on the basis of the data from the State Statistics Committee of the Republic of Uzbekistan

Table 1 shows that there is a strong link between the factors selected by the factor and factors that are interconnected and multicollearity among the factors. Now, we can create a regression equation to determine the relationship between the factors affecting the probable omega. Regression equation shows the functional relationship between the factors selected by the factor and the factors selected. It is desirable to use Eviews to create a regression equation. This is because the program is easy, fast, and at the same time the widest range of criteria for assessing the reliability and adequacy of the model. According to research results:

$$
Y=208+1,4 * X_{1}+1,3 * X_{2}+0,2 * X_{a}
$$

(1)- model was detected

Where: $\mathrm{Y}$ - the size of grains grown;

$\mathrm{X}_{1}$ - investment volume;

$\mathrm{X}_{2}$ - number of threads in the line;

$\mathrm{X}_{3}$ - space allocated.

The reliability and relevance of the model was required to be tested on a specific basis, and the Eviews program employed the Least Squares methods of the Akaike, Schwarz, and Hannan Quinn data sizes. 
Table 2: (1) results of reliability and relevance of the model

\begin{tabular}{|c|c|c|c|c|c|}
\hline R-squared & 0.954835 & Mean dependent var & 1647.189 & \multicolumn{2}{|c|}{$\mathrm{t}_{\text {-Statistic, }} \mathrm{t}_{\mathrm{table}}=2.15$} \\
\hline Adjusted R-squared & 0.945157 & S.D. dependent var & 802.1848 & $\mathrm{t}_{\mathrm{X} 1}$ & 7.880674 \\
\hline S.E. of regression & 187.8609 & Akaike info criterion & 13.50241 & $\mathrm{t}_{\mathrm{X} 2}$ & 2.52201306 \\
\hline Sum squared resid & 494083.9 & Schwarz criterion & 13.70027 & $\mathrm{t}_{\mathrm{X} 3}$ & 1.175759 \\
\hline Log likelihood & -117.5217 & Hannan-Quinn criter. & 13.52969 & $\mathrm{t}_{\mathrm{C}}$ & 2.6556149 \\
\hline Prob(F-statistic) & 0.000000 & Durbin-Watson stat & 1.847819 & & \\
\hline F-statistic & 98.65797 & $\mathrm{~F}_{\text {table }}$ - statistic & 0.114746 & & \\
\hline
\end{tabular}

Source: The author's research results

According to the values of the given table, the (1) model is analyzed by Akaike-AIC $=13.5$, Schwarz-BIC = 13.7 and Hannan-Quinn-HQ = 13.5, Dustin-Watson-DW = 1,85 , which allows to test automobile corrosion. However, because of the importance of the parameter, the criterion $\mathrm{X}_{3}$ of the allocated space should not be satisfied with the ttable $<$ taccount condition defined by the Styudent criterion, but must be evaluated with the mean absolute precentral error (MAPE) and Theil inquIAL coefficient (TIC) picture).

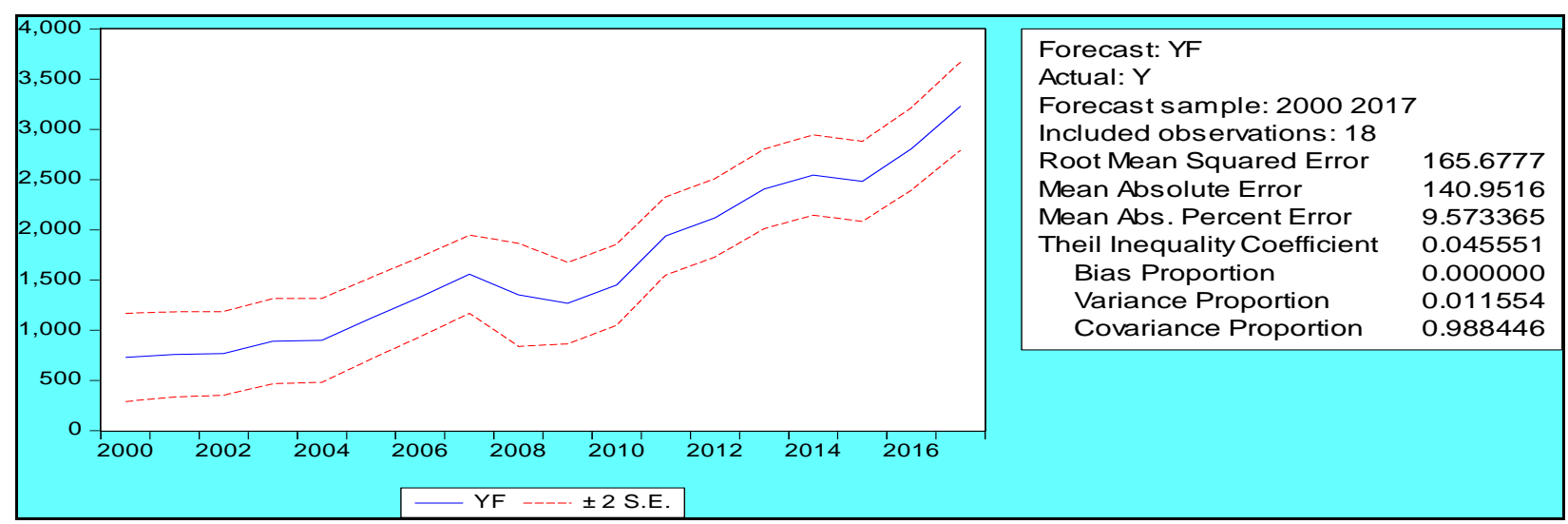

Picture 3. The quality graph of the forecast model

As shown in Figure 3, the quality of the prognosis is excellent and we have MAPE $=9,573<10 \%$, and since the TIC $=0.0455$ in this process, the quality of the forecast is very high and (1) model is reliable and adequate. If we make a cost model for this model (1), the amount of investment required for network development, the number of bus lines and the allocation of the land area to one unit will be increased by 1.4 per cent, respectively; Increased by 1.3 and 0.2 inches. As a matter of fact, the most important factor influencing the growth of the resulting factor is the investment index that requires effective utilization of each investment.

Using the definition (1), it is possible to determine the future multi-dimensional forecast of the volume of fruit

production in the horticulture of the Republic of Uzbekistan. For this, the size of the gross product grows:

$$
Y=208+1,4 * X_{1}+1,3 * X_{2}+0,2 * X_{a}
$$

(1) is defined by determining and replacing the model and its parameters by the time trend calculated.

Investment volume $-X_{1}=-360,1+125,8 * t$;

Number of fields in the network $X_{2}=1,7+0,11 * t ; \quad$ (3)

Area allocated - $X_{3}=139,2+8,1 * t$

Table 4: Multi-factor forecast of fruit production in the Republic of Uzbekistan

\begin{tabular}{|l|c|c|c|c|}
\hline Years & $\begin{array}{c}\text { Gross output } \\
\text { (thousand tons) }\end{array}$ & $\begin{array}{c}\text { Investments made, bn. } \\
\text { soums }\end{array}$ & $\begin{array}{c}\text { Number of employees } \\
\text { in the network, mln. } \\
\text { person }\end{array}$ & $\begin{array}{c}\text { Area allocated } \\
\text { (thousand ea) }\end{array}$ \\
\hline 2018 & 3113,7 & 2030,1 & 3,79 & 293,1 \\
\hline 2019 & 3291,6 & 2155,9 & 3,9 & 301,2 \\
\hline 2020 & 3469,5 & 2281,7 & 4,01 & 309,3 \\
\hline 2021 & 3647,3 & 2407,5 & 4,12 & 317,4 \\
\hline 2022 & 3825,4 & 2533,3 & 4,23 & 325,5 \\
\hline 2023 & 3997,5 & 2659,1 & 4,34 & 333,6 \\
\hline
\end{tabular}

According to the data of the table, by 2023, the volume of horticultural production increased by 333.6 thousand hectares, and the volume of investment in the industry amounted to 2659.1 billion soums. soums and gardening $4,34 \mathrm{mln}$. it is expected that the gross fruit yield will reach
3997.5 thousand tons. This, in turn, will increase by $30 \%$ compared to 2017. Of course, such a positive outcome would be to carry out the task of delivering fruits and vegetables 
to consumers in the future, improving the storage, processing and preventing losses.

In 2014 , the total harvested fruits amounted to 3076.3 thousand tons, accounting for $28 \%, 1.9 \%$, and $3.3 \%$ - to new consumers, $1.4 \%$ lost in 2017 , respectively, $46.6 \%, 3.1 \%$, $5.4 \%$ and $2.3 \%$ respectively. If you look at the outcome of the forecast, it is necessary to conduct an ongoing effort to expand the activities of the expected harvesting and processing enterprises, as well as to mitigate new foreign markets and reduce losses.

It should be noted that the development of the gardening products storage system in the country should be carried out in the following three areas:

- establishment of private or cooperative forms by agricultural producers of gardening products;

- organization of founder's funds and fixed assets of agro-firms within fruit and vegetable agro-industrial companies;

- Agricultural products can be organized at the wholesale markets, on the basis of investments and markets of wholesale markets.

The main source of funding is the production and services sectors, the government's targeted soft loans, bank loans, leasing companies and sponsoring companies.

When organizing the products, they should be sorted separately and placed in containers. In this case:

- By qualitative and quantitative analysis, wholesale and retail buyers save time for their quality and volume;

- Installation of products from the warehouse or at the wholesale sale of the goods at the same time with the installation of their own containers in vehicles will require less expenses, preventing the quality of the product;

- It is possible to increase the level of mechanization of loading, upgrading and discharging of large warehouses.

It is desirable to develop the following areas of expansion of the gardening products storage system in the long term:

- Establishment of large-scale warehouses for fruiting the airflow in the building, controlled by artificial cooling, temperature and humidity;

- Establishment of warehouses for quality control of products using polyethylene masks in frozen food;

- It is important to use the opportunity to build a controlled, air-conditioned small storage facility, which allows for the storage of temperature and humidity in the naturally occurring small and rapidly degrading fruits.

\section{DISCUSSION \& CONCLUSION}

The analysis shows that farms produce cotton, grain and cocoons, and other products, especially fruits and vegetables, are sold through farmer markets. The proportion of product deliveries to the consumer, processing and procurement companies remains low. The product is becoming more and more difficult due to problems such as access to the market, the organization of the transport system, and the purchase of packing materials. This leads to the death of the product or its low cost.

Keeping seasonal storehouses in the storehouse, setting up the necessary conditions for it, controlling the quality change, compliance with storage rules, and the proper organization of sorting, packaging and transportation are a key factor in raising product competitiveness. Due to storage and transportation problems:

- Approximate calculations show that the loss of fruits and vegetables in the country is $30-35 \%$;

- Reduced product quality and, as a result, farmers lose average real earnings of about $20-25 \%$, due to lower product quality;

- The consumer is experiencing poor quality of products, chemical composition and sanitation. This, in turn, affects the health of people who consume.

\section{Theoretical implications}

Analyzes suggest that fruits are imported into the domestic market, with most of the fruits grown out of the market. Therefore, in developing the horticulture industry, there is a need to improve the sales system. This is due to the fact that it is the final stage of the sales sector in the system of production and consumption of goods. Because, in the process of preparation, storage, selection, packaging and sales, consumer value is created, appearance and corrosion increase.

Dehkan markets are very difficult to sell and sell at the right time without breaking the quality. The following factors have a major impact:

- The distance from the market in terms of the location of productive farmers and farms will increase transport costs;

- Long-distance carriages and associated containers and packaging equipment are required for transportation. These tools are not always available at dehkan farms or farms.

- Many farmers and farmers who are producing gardening products are not able to effectively market their products, to study the markets, to find consumers and deliver products to consumers;

- Conjuncture is a fast-changing and seasonal market requires a good market analysis, skilled professionals who have the skills to make analysis based on analysis. Smaller farms do not have such specialists today. Therefore, it is necessary to develop an organized trading system for the sale of goods. By using such a system:

- Saves excess costs associated with selling goods in farms through sales;

- It is possible to effectively sell geographically large crops of small scale farms;

- The opportunity to deliver products to consumers at an affordable and relatively low cost.

The need to organize trade through organized markets (wholesale markets, business entities based on cooperative principle):

- The development of market relations in the market imposes on the farmer the deliveries of the product to the consumer;

- Simultaneously complicated issues such as product development, market research, buyer search, organization of trade, price-fixing issues for gardener; 
- The fact that horticultural farms can not independently control their sales of fully independent and free economic activity.

Nowadays, getting the attention of consumers and farmers who sell their products to the market is the result of additional services. Therefore, it is possible to set up various services for customers through organized sales.

\section{Practical implications}

For the sustainable development of gardening it is expedient to solve the following organizational and economic problems in the field:

- Reproduction of high-yielding, resistant to diseases and pests, rapidly changing varieties of fruit-bearing trees resistant to unfavorable natural conditions and meeting market demand, and taking into account the level of compliance with the condition of the territories;

- Introduce mechanisms to encourage investment in material and technical re-equipment of water supply systems in the gardening (through targeted and preferential loans from the state, various grants, private sector funds and other financial sources);

- Improvement of the system of mineral fertilizers, taking into account scientifically-based agrotechnical rules in the field, taking into account soil composition, types and varieties of fruit trees;

- optimize the composition of fruit trees, taking into account the regional markets and exports;

- solution of the problem of provision of the network with gardening equipment, repair of existing equipment and provision of spare parts;

- Improvement of irrigation techniques and technologies in the conditions of water scarcity (establishment of wide use of micro and drip irrigation methods);

- restoration of existing old gardens, replacement of low-yielding gardens with fruit-bearing fruit trees, using new technologies in creating new gardens;

- Improvement of the professional skills of managers of farms established in the field of gardening, assistance in the implementation of new agro-technical measures for the care of gardens, and improving the economic basis of providing gardeners with qualified specialists.

Improving the composition of fruiting gardens should be carried out taking into account the characteristics of the region. At the same time, when placing the varieties and varieties of fruit trees, it is necessary to take into account not only the natural and climatic conditions of the region, but also the characteristics of the soil and its chemical and mechanical properties.

\section{REFERENCES}

[1] Ushacheva I.G., Ogloblina E.S., Sandu I.S., Trubilina A.I. (2006) Innovative activity in the agro-industrial complex of Russia. Collective monograph. - M .: "Economics and Informatics", - 374 p.

[2] Chemeris E.M. (2014) Agricultural Competitiveness (Managerial Aspect): Monograph. Bishkek: KRSU, 184 p.

[3] Basiago A.D. (1999) Economic, social, and environmental sustainability in development theory and urban planning practice. Kluwer Academic Publishers, Boston. Manufactured in the Netherlands. The Environmentalist 19, 145-161 pp.
[4] James McEldowney (2017) Urban agriculture in Europe. Members Research Service Directorate-General for Parliamentary Research Services, European Parliament. ISBN 978-92-846-2506-2. doi:10.2861/413185

[5] Asfaw, A. 2008. Fruits and vegetable availability for human consumption in Latin American and Caribbean countries: Patterns and determinants. Food Policy. 33: 444-454. Andretta, S. 1998

[6] Kumar B.M, and P.K.R. Nair. (2004). The enigma of Tropical Homegardens. In New vistas in agroforestry: a compendium for the 1st World Congress of Agroforestry. Kluwer Academic Publishers. Pp. 135-152.

[7] Rojo S.et al.,(2015) 'From urban food gardening to urban farming', Chapter 1.2 in F. Lohberg, L. Licka, L. Scazzosi and A. Timpe (eds.), Urban Agriculture Europe, Jovis, 2015.

[8] Keeffe G. (2016). Hardware software interface - A strategy for the design of urban agriculture. in R. Roggema (ed.), Sustainable urban agriculture and food planning, Routledge, pp. 15-37.

[9] Jenkins A., Keeffe G. and Hall N. (2015). Planning urban food production into today's cities. Future of Food: Journal on Food, Agriculture and Society, 3 (1), pp 35-47.

[10] Opitz I., Berges R., Piorr A. and Krikser T. (2016). Contributing to food security in urban areas: differences between urban agriculture and peri-urban agriculture in the Global North, Agriculture and Human Values, Vol. 33, pp. 341- 358.

[11] Bahodirzhan B. (2017) Economic Mathematic-Statistical Modeling in Distribution of Investments in Uzbekistan. J Bus Fin Aff 6: 281. doi: 10.4172/2167-0234.1000281.

[12] Sinha J.K. (2017) Contribution of investment in economic growth of major sectors: With focus on agriculture and allied sector in Bihar. Statistical Journal of the IAOS 33 (2017) 557-564 557 do 10.3233/SJI-160318 IOS Press.

[13] Russia in 2018 will regain its world leadership in the ranking of the largest importers of apple - a forecast. https://east-fruit.com/article/rossiya-v-2018.

[14] Belykh A.M. (2006). Agroclimatic zoning of fruit and berry crops in the Novosibirsk region. / Gardening and viticulture. -Moscow, -№ 1 - p. 2-4

[15] Shalyapina I.P. (2006). Gardening System. / Agrarian Science. -Moscow, -№ 7 -C.15-18.

[16] Shalyapina I.P. (2008). Improving the efficiency of fruit storage. / Agrarian science. -Moscow, -№ 3 -C. 30-33.

[17] Mullabaev B.B. Development of light industry branches in uzbekistan basedon vertical integration // Bulletin ofScience and Practice scientific journal No. 10 of 2017 http://www.bulletennauki.com 